\title{
Endometrial tuberculosis among patients undergoing endometrial biopsy at Tikur Anbesa specialized hospital, Addis Ababa, Ethiopia
}

\author{
Sileshi Abdissa ${ }^{1,2}$, Tamrat Abebe ${ }^{2}$, Gobena Ameni ${ }^{3}$, Sisay Teklu4 ${ }^{4}$, Yonas Bekuretsion ${ }^{5}$, Markos Abebe ${ }^{6}$
} and Adane Mihret ${ }^{2,6^{*}}$ (D)

\begin{abstract}
Background: Female genital tuberculosis (FGTB) is known to cause severe tubal disease leading to infertility and its incidence closely parallels with the overall prevalence of tuberculosis (TB) in a community. Its magnitude is underreported because diagnosis is difficult and requires invasive techniques. In this study we determined the prevalence of endometrial tuberculosis and characterized isolates among women who underwent endometrial biopsy for evaluation of various conditions at a Tikur Anbessa Specialized Hospital (TAHS), Addis Ababa, Ethiopia.

Methods: A cross sectional study was conducted on 152 consecutive gynecologic patients who underwent endometrial biopsy for different gynecologic diseases. Endometrial tissue taken for routine histopathology examination was shared after informed consent was obtained from the patient and subjected to polymerase chain reaction (PCR) and culture for Mycobacterium tuberculosis (Mtb).

Results: The prevalence of endometrial TB in this study by IS1081PCR was 4.6\% (7/152) while culture proven endometrial TB was 2.6\% (4/152). However, histological examination identified only 2/152 (1.3\%) endometrial tuberculosis. While all culture proven TB samples were also PCR positive for Mtb, only one histologic proven endometrial TB was culture and PCR positive. All of the four isolates by culture were M. tuberculosis.
\end{abstract}

Conclusion: This study has shown that the magnitude of endometrial TB is fairly high in gynecologic patients visiting outpatient departments for various complaints and PCR detects more cases than culture or Histopathology.

Keywords: Endometrium, Tuberculosis, Mycobacterium tuberculosis

\section{Background}

Tuberculosis (TB) predominately presents with pulmonary disease, although extra-pulmonary TB (EPTB) is not uncommon [1]. Genitourinary $\mathrm{TB}$, comprising about $30 \%$ of all $\mathrm{TB}$, is the second most common form of extrapulmonary TB [2]. The prevalence of FGTB increases in countries with a high burden of high Pulmonary Tuberculosis (PTB). Five to $13 \%$ of all PTB patients develop GTB [3].

\footnotetext{
* Correspondence: Adane_mihret@yahoo.com

${ }^{2}$ Department of Microbiology, Immunology and Parasitology, School of

Medicine, Addis Ababa University, Addis Ababa, Ethiopia

${ }^{6}$ Armauer Hansen Research Institute, Addis Ababa, Ethiopia

Full list of author information is available at the end of the article
}

In addition to the subtle presentation of the disease, the low sensitivity and specificity of routine diagnostic methods and the paucity of the organism in clinical samples are the main factors for the lower detection of genital TB (GTB) [4]. Therefore, the use of advanced techniques such as PCR as part of diagnosis is crucial in defining the magnitude of the problem and alerting early investigation, before serious complications occur. Most cases of GTB are secondary to gastrointestinal TB spreading to the fallopian tubes causing TB salpingitis. Further spread of the organism involves the uterine endometrium (50\%), ovaries $(10-30 \%)$, cervix (3\%), and vagina and vulva $(<1 \%)$ [5]. The most frequent symptom of FGTB is infertility, as a result of irreversible damage to the fallopian tube [6]. TB

(c) The Author(s). 2018 Open Access This article is distributed under the terms of the Creative Commons Attribution 4.0 International License (http://creativecommons.org/licenses/by/4.0/), which permits unrestricted use, distribution, and reproduction in any medium, provided you give appropriate credit to the original author(s) and the source, provide a link to the Creative Commons license, and indicate if changes were made. The Creative Commons Public Domain Dedication waiver (http://creativecommons.org/publicdomain/zero/1.0/) applies to the data made available in this article, unless otherwise stated. 


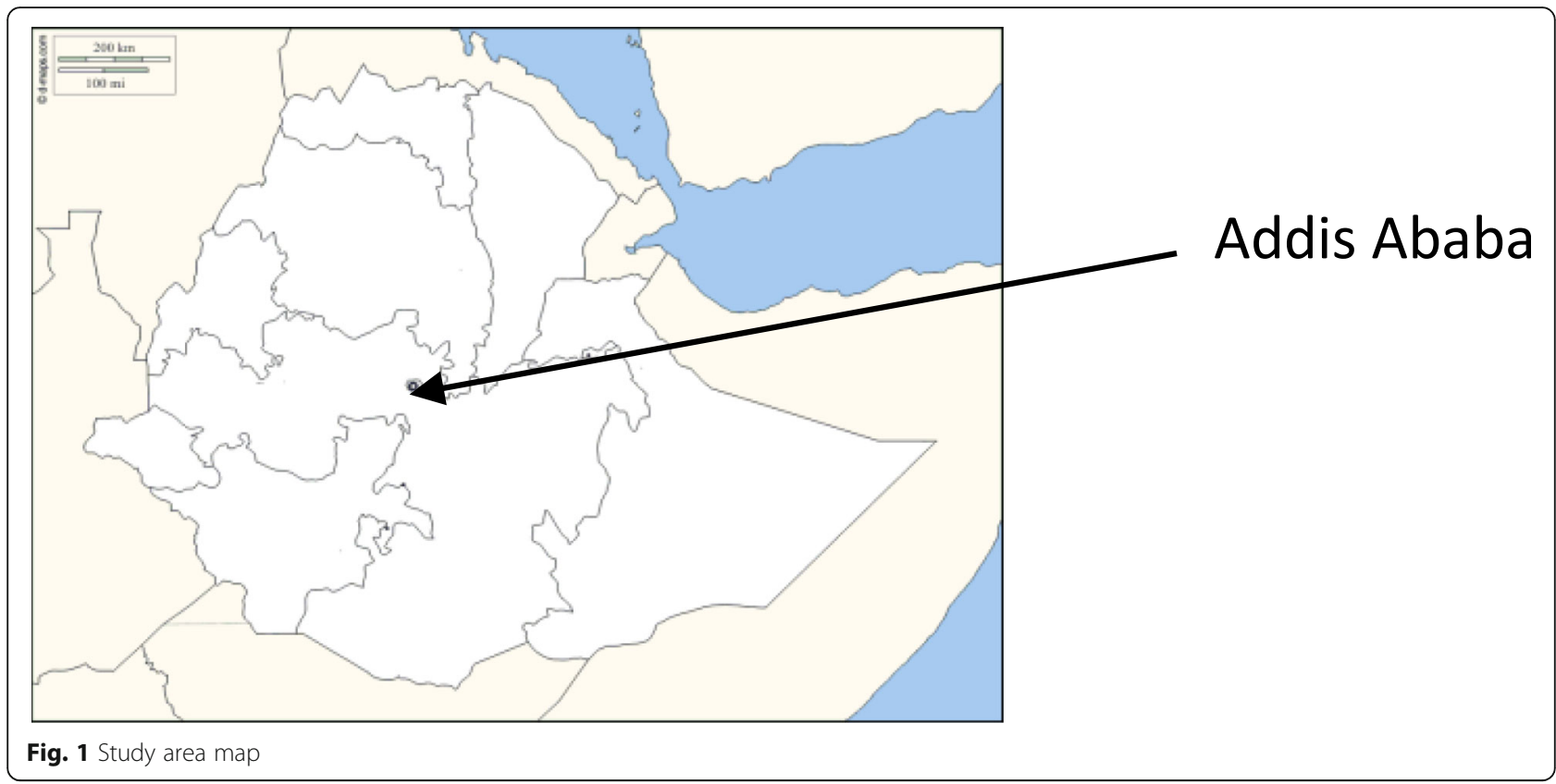

salpingitis and endometritis are responsible for 5 to $20 \%$ of all causes of infertility [7, 8], and up to $39-41 \%$ in women with tubal factor infertility. Peritubal adhesions and pelvic masses were detected in most patients with GTB [9]. Women with GTB have a low fertility rate varying from 16 to $38.2 \%$ [6, 9]. Although most cases of GTB are asymptomatic, chronic pelvic inflammatory disease, menstrual irregularities, low grade fever, loss of weight and appetite, and tubo-ovarian masses are manifestations of GTB $[10,11]$. Depending upon the damage to the uterine cavity and the endometrium, uterine tuberculosis can be described as mild, moderate, or severe [9].

Based on the epidemiology of TB and Ethiopia being one of the high TB burden countries, FGTB could also be a common gynecologic problem in Ethiopia. However, there is limited information on the epidemiology of FGTB in general and endometrial TB in particular, in Ethiopia. Studying the concordance of the different laboratory tests with clinical diagnosis is very important to choose the method with better sensitivity. The main purpose of this study was to determine the prevalence of endometrial tuberculosis and to characterize isolates among patients undergoing endometrial biopsy for histo-pathological examination, for gynecologic diseases, at Tikur Anbessa Specialized Hospital, using culture and PCR techniques, and to compare the three methods.

\section{Methods}

\section{Study design and population}

An observational cross-sectional, hospital-based study was conducted on 152 women who attended the TASH gynecology outpatient department, Addis Ababa, Ethiopia
(Fig. 1). All study participants were gynecologic patients for whom endometrial biopsy was requested for different indications during the period of December 2011-August 2012. All participants gave written informed consent to participate in the study and the study adheres to STROBE guidelines. Fresh, leftover biopsy sample was taken and added aseptically into sterile universal bottles in $5 \mathrm{ml}$ of $0.85 \%$ saline solution. It was transported as soon as possible in an ice box at a temperature of $4{ }^{\circ} \mathrm{C}$ to laboratory and was processed accordingly.

\section{Laboratory methods Histopathology}

The specimen was transported to the TASH pathology lab in $10 \%$ formalin. After gross description by a pathologist, it was transferred into plastic cassettes and processed using Tissue Tek II VIP processor and then embedded in paraffin. After sectioning, it was stained by the Hematoxylin \& Eosin (H\&E) stain using a Leica autostainer. The Presence of caseating granulomas surrounded by epitheloid cells, lymphocytes, plasma cells and giant cells were diagnostic of tuberculosis.

\section{Culturing and identification of Mycobacterium}

Specimen processing and culturing for isolation of Mycobacterium tuberculosis was carried out in the TB laboratory of Akililu Lemma Institute of Patho-Biology (ALIPB) and at the Armauer Hansen Research Institute (AHRI). In the laboratory, the tissue sample was homogenized using $0.5-1 \mathrm{ml}$ sterile saline after sectioning each tissue specimen into fine pieces with a sterile scalpel or scissor. The 
Table 1 Socio-demographic characteristics of study participants, Tikur Anbessa Specialized Hospital, Addis Ababa, Ethiopia

\begin{tabular}{|c|c|c|c|}
\hline Socio-demographic characteristics & Range & Frequency $(N=152)$ & Percent \\
\hline \multirow[t]{8}{*}{ Age } & $20-26$ & 16 & 10.5 \\
\hline & $27-33$ & 31 & 20.4 \\
\hline & $34-40$ & 54 & 35.5 \\
\hline & $41-47$ & 23 & 15.1 \\
\hline & $48-54$ & 19 & 12.5 \\
\hline & $55-61$ & 5 & 3.3 \\
\hline & $62-68$ & 2 & 1.3 \\
\hline & $>/=69$ & 2 & 1.3 \\
\hline \multirow[t]{2}{*}{ Region } & Addis Ababa & 89 & 58.6 \\
\hline & Outside Addis Ababa & 63 & 41.4 \\
\hline \multirow[t]{4}{*}{ Marital status } & Unmarried & 29 & 19.1 \\
\hline & Married & 111 & 73 \\
\hline & Divorced & 8 & 5.3 \\
\hline & Widowed & 4 & 2.6 \\
\hline
\end{tabular}

homogenate was then decontaminated as per Kubica [12] using 4\% $\mathrm{NaOH}$ for $15 \mathrm{~min}$ and centrifuged at $3000 \mathrm{rpm}$ for another $15 \mathrm{~min}$. Two drops of phenol red indicator were added to the sediment after the supernatant was discarded and $2 \mathrm{M} \mathrm{HCl}$ was added to neutralize. Neutralization was deemed to be achieved when the color of the solution is changed from purple to yellow. Then the sediment was inoculated immediately onto culture medium and incubated at $37{ }^{\circ} \mathrm{C}$. The incubation period was for at least 8 wks, with weekly observation for discernible growth. Identification was based on morphology, color, rate of growth, and the acid-fastness was confirmed by Ziehl-Neelsen (ZN) staining) [13]. Thereafter, isolates from the positive cultures were preserved by freezing, while at the same time an aliquot was heat-killed ina water bath at $80{ }^{\circ} \mathrm{C}$ for $1 \mathrm{~h}$. The frozen and heatkilled isolates were stored at $-20{ }^{\circ} \mathrm{C}$ for further mycobacteriology and molecular typing analysis.

\section{Region of difference based PCR}

Isolates were confirmed as $M$. tuberculosis by deletion typing of the Region of Difference (RD) using 9 regions according to a previously described PCR protocol [14]. The status of the RD9 region (deleted or intact) was assessed by multiplex PCR with a set of three primers (primer set RD9): two primers targeting the flanking regions of RD9 (RD9_Fw, 5' - AAC ACG GTC ACG TTG TCG TG -3', RD9_Rev, 5' - CAA ACC AGC AGC TGT CGT TG -3'and one primer hybridizing with the internal

Table 2 Clinical profile of study participants, Tikur Anbessa specialized hospital, Addis Ababa, Ethiopia

\begin{tabular}{|c|c|c|c|c|c|c|}
\hline \multirow{2}{*}{\multicolumn{2}{|c|}{ Clinical background }} & \multirow{2}{*}{$\begin{array}{l}\text { Frequency } \\
\text { (Total 152) }\end{array}$} & \multirow{2}{*}{$\begin{array}{l}\text { Relative } \\
\text { frequency }\end{array}$} & \multicolumn{2}{|c|}{ Endometrial TB } & \multirow{2}{*}{$\begin{array}{l}\text { Positive } \\
\%\end{array}$} \\
\hline & & & & Culture & IS1081-PCR only & \\
\hline \multicolumn{2}{|l|}{ Primary infertility } & 43 & 28.3 & 1 & 3 & 7.7 \\
\hline \multicolumn{2}{|c|}{ Secondary infertility } & 22 & 14.5 & 1 & 0 & \\
\hline \multicolumn{2}{|c|}{ Investigated for infertility problem } & 29 & 19.1 & 2 & 2 & 13.8 \\
\hline \multicolumn{2}{|c|}{ Menses disturbance } & 112 & 73.7 & 1 & 2 & 2.8 \\
\hline & Menorrhagia & 67 & 59.8 & 1 & 0 & \\
\hline & Amenorrhea & 24 & 21.4 & 0 & 1 & \\
\hline & Oligomenorrhea & 21 & 18.8 & 0 & 1 & \\
\hline \multicolumn{2}{|c|}{ Chronic Pelvic pain } & 90 & 59.2 & 4 & 2 & 6.7 \\
\hline \multirow[t]{3}{*}{ HIV screen result } & Positive & 9 & 5.9 & 0 & 0 & 0.0 \\
\hline & Negative & 99 & 65.1 & 2 & 2 & 4.0 \\
\hline & Undetermined & 44 & 28.9 & 2 & 1 & 6.8 \\
\hline \multicolumn{2}{|c|}{ Anti TB before 2 years } & 13 & 8.5 & 0 & 0 & 0.0 \\
\hline
\end{tabular}


Table 3 Detection of M. tuberculosis with different diagnostic methods, Tikur Anbessa Specialized Hospital, Addis Ababa, Ethiopia

\begin{tabular}{lll}
\hline Assays & No. of samples & Positive result (\%) \\
\hline PCR-IS1081 & 152 & $7(4.6)$ \\
Culture with AFB confirmed & 152 & $5(3.3)$ \\
Culture with species confirmed & 152 & $4(2.6)$ \\
Histo-pathology & 152 & $2(1.3)$ \\
Combination of Culture and IS1081-PCR & 152 & $7(4.6)$ \\
All tests & 152 & $8(5.3)$ \\
\hline
\end{tabular}

region of RD9 (RD9_IntRev, 5' - TTG CTT CCC CGG TTC GTC TG -3'. Using agarose gel electrophoresis, a PCR product of 396 bp was interpreted as that RD9 was present (i.e. M. tuberculosis). The presence of a 707 bp deletion confirmed Mycobacterium. africanum or Mycobacterium. bovis.

The PCR mixture used to detect RD contained $2 \mu \mathrm{l}$ of heat-killed mycobacterial DNA, a final concentration of $10 \mu \mathrm{l}$ Hot Start Taq master mix (Qiagen), $0.3 \mu$ primers RD9_FW, RD9_Rev, and RD9_IntRev $(100 \mu \mathrm{M})$, and $7.1 \mu \mathrm{l}$ sterile distilled water to a final volume of $20 \mu \mathrm{l}$. Thermal cycling was performed with a T-3000 Thermocycler Biometra Amplifier with an initial denaturation step of $15 \mathrm{~min}$ at $96{ }^{\circ} \mathrm{C}, 35 \mathrm{cy}$ cles of $30 \mathrm{~s}$ at $96{ }^{\circ} \mathrm{C}, 30 \mathrm{~s}$ at $55{ }^{\circ} \mathrm{C}$, and $1 \mathrm{~min}$ at $72{ }^{\circ} \mathrm{C}$, followed by a final elongation step of $10 \mathrm{~min}$ at $72{ }^{\circ} \mathrm{C}$. PCR products were separated on a $1 \%$ agarose gel.

\section{Statistical analysis}

Data were entered and cleared using EpiData version 3.1.Then they were exported to SPSS software version 20 for analysis.

Descriptive statistics were used for age, marital status, region of the participant, and to determine the prevalence of endometrial TB. The mean and standard deviation for age was also calculated. Crosstabs (kappa) was used for clinical diagnosis versus lab result, and for method evaluation respectively.

\section{Results}

\section{Sociodemographic characteristics}

As shown in Table 1, most of the study participants were in the age group of $34-40$ years (mean age being $38.37 \pm 10$ years) and married.

Table 2 shows that the major complaint of the study participants was menstrual disturbance $(73.7 \%)$ followed by chronic pelvic pain (59.2\%). Endometrial TB was found by one of the three tests in $6.7 \%(6 / 90)$ of patients who were having chronic pelvic pain and in $7.7 \%(5 / 65)$ of the women complaining of infertility. During recruitment, 29 women were investigated for infertility and $13.8 \%(4 / 29)$ were positive for endometrial TB. Only $71 \%$ of the participants were voluntarily screened for HIV and none of HIV positives had endometrial TB.

\section{Prevalence of endometrial tuberculosis}

The prevalence of endometrial TB was determined by culture with species confirmed by RD and IS1081-PCR for MTC. Consequently, 7(4.6\%) were found to be members of the MTB complex (MTBC) byIS1081-PCR, of which only $4(2.6 \%)$ were culture positive and confirmed as $M$. tuberculosis by RD (Table 3 ).

\section{RD based species identification and multiplex PCR genus typing}

After confirming the acid fastness of the isolates from the culture by Ziehl-Neelsen, further investigation was conducted to differentiate the species among the MTBC

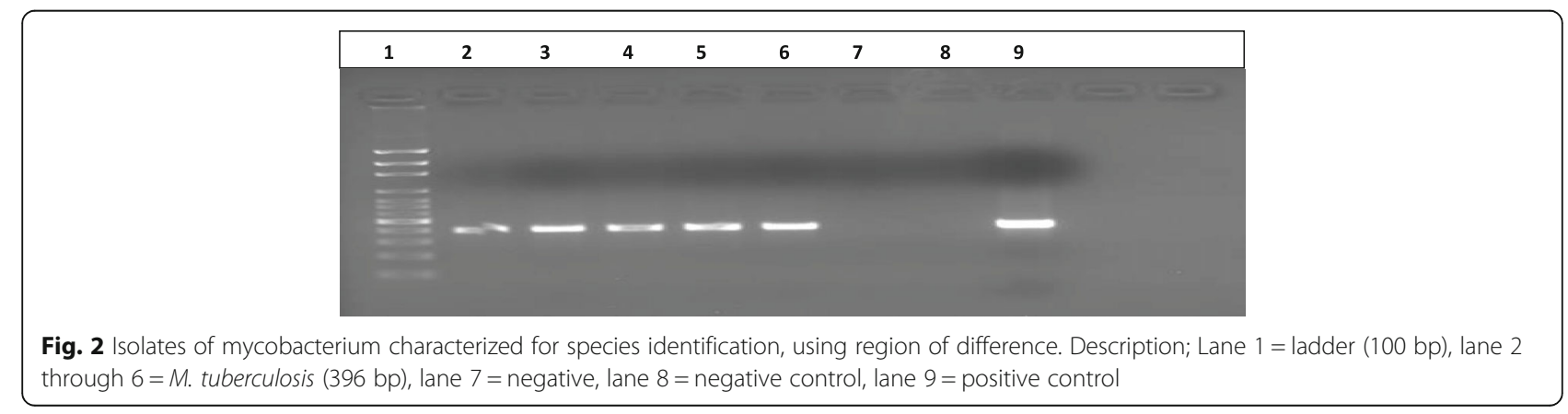


Table 4 Clinically suspected endometrial TB versus the rate of positivity by culture and/or IS1081-PCR

\begin{tabular}{llllllll}
\hline & Total $(n=152)$ & \multicolumn{1}{l}{ Culture + IS1081-PCR } & Sensitivity \% & Specificity \% & PPV \% & NPV \% & kappa \\
\hline Clinically Suspected for TB & & Positive & Negative & & & & \\
& Yes & 2 & 4 & 28.6 & 97.2 & 33.3 & 96.6 \\
& No & 5 & 141 & & & & \\
\end{tabular}

by the presence or absence of RD9. All culture positive AFB confirmed were M.tuberculosis (RD9 present) (Fig. 2), except one, which was later confirmed as not being a member of MTBC or even of the genus Mycobacterium by typing.

\section{Agreement between clinical criteria and culture and/or IS1081 PCR}

The distribution of endometrial TB among suspected and non-suspected cases was analyzed and found to be prevalent in patients that had not been suggested by the physicians $(71.4 \%$, or $5 / 7)$ with the measure of agreement (kappa) 0.28 (Table 4) with both culture and/or IS1081-PCR and 75\% of participants, who were culture positive only, were not suspected by physicians, with a kappa value of 0.17 (Table 5).

\section{Evaluation of histopathological examination and IS1081- PCR with culture}

The performance of histopathological examination and IS1081-PCR were evaluated against culture (Fig. 3). All culture positive samples were positive by IS1081-PCR, and one of two samples (50\%) sample had a concordant result between histopathology and culture (Table 6).

\section{Discussion}

In this population of women who underwent endometrial biopsy for different gynecologic indications, it was found that the prevalence of endometrial TB was $4.6 \%$ by PCR, $2.6 \%$ by culture and $1.3 \%$ by histopathologic examination, showing a high prevalence rate similar to communities with a high overall TB prevalence rate [7-11, 15]. Since only endometrial samples were studied this will underestimate the prevalence and may not give the full picture about the occurrence of female genital TB. A similar study in India on general gynecological admissions identified $2.8 \%$ of GTB and $7.2 \%$ from infertile cases with a gynecological problem, with the help of a simplified TB algorithm [16]. The inclusion of mycobacteriological tests and molecular techniques could account for the higher report in our study though India is among the high TB burden countries.

Most studies in Africa and other Asian countries have given attention only to infertile women in order to assess the contribution of GTB to infertility, to understand the related clinical signs and symptoms and the consequence of treatment on conceiving. Our study identified endometrial TB in $6.7 \%$ of patients with chronic pelvic pain, $7.7 \%$ of women who had a problem of conception and in $13.8 \%$ of women who underwent endometrial biopsy as part of an infertility workup. A report from Tyerberg Hospital of South Africa, a country with a higher TB burden than Ethiopia, showed an incidence of $6 \%$ culture positive GTB in an infertile population [17]. A similar study conducted in India using hysterosalpinography [HSG] identified 6.3\% GTB from all patients who underwent through the procedure which is in agreement with our study [18]. Similar to studies done in India, all positive cases were in the reproductive age group [19-21].

Of 152 women studied, 112 had one or another form of menstrual abnormality. Endometrial TB was detected in $2.8 \%$ of women with menstrual abnormality, similar to another study [22].

Literature reveals that M. tuberculosis is the most predominant species among the MTC species [23]. Similarly, in the present study, all isolates except one were confirmed as $M$. tuberculosis by deletion typing. One isolate, which was not in the genus Mycobacterium, could be an organism such as Actinomycesor Nocardia, that are known to cause pulmonary, cutaneous and sub-cutaneous diseases. They are acid fast by Ziehl Neelson staining, as is Rhodococcus equi, that causes pneumonia and is an acid fast cocco bacillus [24, 25]. Active GTB diagnosis was suggested by characteristic features of HSG, evidence of calcification/ complex adnoxal mass by scan, and the contact history of the patients. As a result, six patients were identified with possible GTB and two were positive for endometrial TB. One patient was positive by culture, IS1081-PCR and histology, but the other was detected only by IS1081-PCR. The overall

Table 5 Clinically suspected endometrial TB versus t rate of positivity by culture

\begin{tabular}{|c|c|c|c|c|c|c|c|c|}
\hline & Total $(n=152)$ & Culture & & Sensitivity \% & Specificity \% & PPV \% & NPV \% & kappa \\
\hline \multirow[t]{3}{*}{ Clinically Suspected for TB } & & Positive & Negative & 25.0 & 96.6 & 16.7 & 97.9 & 0.174 \\
\hline & Yes & 1 & 5 & & & & & \\
\hline & No & 3 & 143 & & & & & \\
\hline
\end{tabular}


Table 6 Comparison of IS1081-PCR and histopathology versus culture

\begin{tabular}{|c|c|c|c|c|c|c|c|c|}
\hline \multirow[t]{2}{*}{ Assays } & \multirow{2}{*}{$\begin{array}{l}\text { Result Total } \\
(n=152)\end{array}$} & \multicolumn{2}{|c|}{ culture positive with species confirmed } & \multirow[b]{2}{*}{ Sensitivity (\%) } & \multirow[b]{2}{*}{ Specificity (\%) } & \multirow[b]{2}{*}{ PPV (\%) } & \multirow[b]{2}{*}{ NPV (\%) } & \multirow{2}{*}{$\begin{array}{l}\text { Kappa } \\
\text { value }\end{array}$} \\
\hline & & Positive & Negative & & & & & \\
\hline \multirow[t]{2}{*}{ IS1081-PCR } & Positive & 4 & 3 & 100 & 98 & 57 & 100 & 0.718 \\
\hline & Negative & 0 & 145 & 25 & 50 & 50 & 98 & 0.321 \\
\hline \multirow[t]{2}{*}{ Histology } & Positive & 1 & 1 & & & & & \\
\hline & Negative & 3 & 147 & & & & & \\
\hline
\end{tabular}

kappa agreement, between clinical criteria and culture and/or IS1081 and culture only was found to be 0.28 and 0.17 respectively. Endometrial TB was more prevalent in patients not suspected of GTB (71.4\%). This could be due to latent infection, when women are still asymptomatic, with low number of bacilli, and before structural damage to the tubes has taken place.

Rapid diagnosis and treatment of EPTB is required to lessen morbidity and mortality due to TB. It is crucial to have a sensitive and specific methodology for the diagnosis of TB in biopsies from genital organs in order to manage the disease easily. Different researchers have evaluated the performance of PCR compared to the conventional culture method in the diagnosis of $\mathrm{TB}$ from body fluid and biopsies. However, the primers used and the nature of the sample determines its sensitivity and specificity. In our findings, all culture positive samples (4/4) were also positive by IS1081-PCR with sensitivity, specificity, PPV and NPV of 100, 98, 57 and 100\% respectively. Other researchers who evaluated IS1081-PCR from lymph node [26] and plural effusion [27] showed that the sensitivity was 91 and $84.6 \%$ respectively. Positive agreement between culture and IS1081-PCR was observed as 0.718 , indicating good agreement. In contrast, Derese et al. reported $23.4 \%$ sensitivity on comparison of IS1081-PCR with standard culture from lymph node [28]. It is likely that the increased sensitivity of

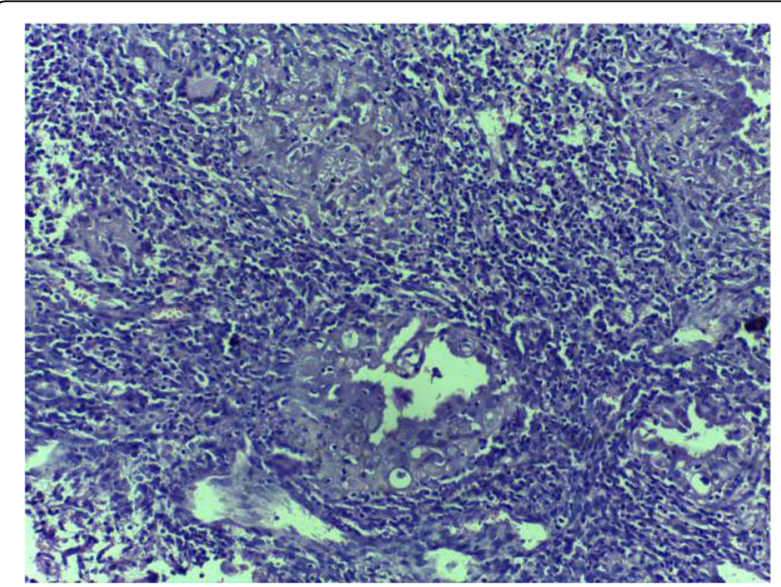

Fig. 3 Endometrium with tuberculosis showing epitheloid cell aggregates and Langhan's giant cells
IS1081-PCR in our results reflects the small number of culture positive samples, good lysis of the mycobacterial cell wall and dissociation of DNA from particulate matter in the crude homogenate, allowing the recovery of supernatant after centrifugation and sufficient sample for extraction. The three (2\%) culture negative but IS1081-PCR positive samples may be discrepant due to the presence of dead bacilli caused by storage or decontamination, and/or the absence or few bacteria in the culture sample.

Histopathology examination (HPE) is easy, quick and cheap. It is routinely used for the diagnosis of GTB, providing characteristic features of $M$. tuberculosis [29]. The primary aim of sample collection in this study was to examine HPE using haematoxylin and eosin staining for routine diagnosis of cancer and other diseases. Accordingly, two (1.3\%) samples were positive for endometrial tuberculosis. One sample gave a concordant result with both culture and IS1081-PCR, but the other was negative by both methods. The agreement between culture and histopathology was found to be 0.321 . A study in India [19] revealed that histopathology was more sensitive (6.9 Vs. 5.6), when compared against clinical criteria that indicated probable GTB, using HSG, laparascopy, ultrasound and other hematological tests. The possible reasons for the lower sensitivity of HPE in the present study could be the cyclical shedding of the endometrium that does not allow granuloma formation. Also, the sampled site may not represent the infected area.

The limitations of this study include the relatively small number of genital tuberculosis patients, which resulted in an inability to assess the sensitivity and accuracy of the different methods to diagnose female genital TB. Moreover, we included all patients for whom endometrial biopsy was requested for different indications and only endometrial samples were studied which might underestimate the prevalence and not give the full picture about the occurrence of female genital TB.

\section{Conclusions}

The present finding of a $4.6 \%$ EPTB prevalence is alarming, especially its widespread distribution throughout the population. Similar to pulmonary and other extra-pulmonary 
TB, the causative agent of GTB was found to be $M$. tuberculosis in this study. Most patients positive for endometrial TB were not suspected by physical examination using clinical criteria. In the diagnosis of endometrial TB, IS1081-PCR was more sensitive and specific than histology or culture, even though culture is regarded as the gold standard. Therefore, using IS1081-PCR and/or culture for screening of GTB could greatly improve the sensitivity of diagnosing FGTB.

\section{Abbreviations \\ AAEC: AHRI/ALERT ethical committee; AHRI: Armauer Hansen Research Institute; ALIPB: Akililu lemma institute of patho-biology; DERC: Departmental ethical review committee; DMIP: Department of medical microbiology, immunology and parasitology; EPTB: extra-pulmonary TB; \\ FGTB: Femalegenital tuberculosis; PCR: Polymerase chain reactio; PTB: Pulmonary tuberculosis; RD: Region of difference; TAHS: Tikur anbessa specialized hospital; TB: Tuberculosis; ZN: Ziehl-neelsen}

\section{Acknowledgements}

We acknowledge staff of Armauer Hansen Research Institute and Aklilu Lemma Institute of Pathobiology tuberculosis unit for their tremendous support. We would like to specially thank all of the patients who agreed to participate in this study.

\section{Funding}

This study was supported by AHRI core funding. The funding body had no any role in the design of the study and collection, analysis, and interpretation of data and in writing the manuscript.

\section{Availability of data and materials}

The data set supporting the conclusion is available upon request the corresponding author

\section{Authors' contributions}

SA: made a substantial contribution to the conception of the study, data collection, data analysis and manuscript writing. TA, GA, MA and AM: Study design, supervision, data analysis and manuscript writing. YB and ST: Study participants recruitment, data collection, analysis and manuscript writing. All of the authors read and approved the final manuscript

\section{Ethics approval and consent to participate}

All of the patients who participated in this study signed an informed consent form. This protocol was approved by the Ethical Review Committee of department of Medical Microbiology, Immunology and Parasitology (DMIP), College of Health Science, Addis Ababa University, AHRI/ALERT Ethical Committee (AAEC), and department of Gynecology and Obstetrics of Tikur Anbessa Specialized Hospital.

\section{Consent for publication}

Not applicable.

\section{Competing interests}

The authors declare that they have no competing interests. The authors alone are responsible for the content and writing of this paper.

\section{Publisher's Note}

Springer Nature remains neutral with regard to jurisdictional claims in published maps and institutional affiliations.

\section{Author details}

'Arsi University, Asella, Ethiopia. ${ }^{2}$ Department of Microbiology, Immunology and Parasitology, School of Medicine, Addis Ababa University, Addis Ababa, Ethiopia. ${ }^{3}$ Aklilu Lemma Institute of Pathobiology, Addis Ababa University, Addis Ababa, Ethiopia. ${ }^{4}$ Department of Gynecology and Obstetrics, School of Medicine, Addis Ababa University, Addis Ababa, Ethiopia. ${ }^{5}$ Department of Pathology, School of Medicine, Addis Ababa University, Addis Ababa, Ethiopia. ${ }^{6}$ Armauer Hansen Research Institute, Addis Ababa, Ethiopia.
Received: 6 September 2017 Accepted: 22 June 2018

Published online: 05 July 2018

\section{References}

1. Tripathy SN, Tripathy SN. Infertility and pregnancy outcome in female genital tuberculosis. Int J Gynaecol Obstet. 2002;76:159-63.

2. Weinberg AC, Boyd SD. Short-course chemotherapy and role of surgery in adult and pediatric genito-urinary tuberculosis. Urology. 1988;31:95.

3. Madhu N, Davinder P. Genital tuberculosis: present scenario. JK Sciece. 2001; 3(4):20-5.

4. Bhanu NV, Singh UB, Chakraborty M, Suresh N, Arora J, Rana T, et al. Improved diagnostic value of PCR in the diagnosis of female genital tuberculosis leading to infertility. J Med Microbiol. 2005;54:927-31.

5. Nogales-Ortiz F, Tarancón I, Nogales FF Jr. Pathology of female genital tuberculosis: a 31 year study of 1436 cases. Obstet Gynaecol. 1979:53:422-8.

6. Parikh FR, Nadkarni SG, Kamat SA. Genital tuberculosis a major pelvic factor causing infertility in Indian women. Fertile Steril. 1997;67(3): 497-500

7. Jahromi NB, Parsanezhad ME, Ghane-Shirazi R. Female genital tuberculosis and infertility. Int J Gynaecol Obstet. 2001;75:269-72.

8. Saracoglu OF, Mungan T, Tanzer F. Pelvic tuberculosis. Int J Gynaecol Obstet. 1992;37(2):115-20.

9. de Vynck WE, Kruger TF, Joubert JJ, Scott F, van der Merwe JP, Hulme VA, Swart Y. Genetal tuberculosis associated with female infertility in west cape. S Afr Med J. 1990;77(12):630-1.

10. Varma TR. Genital tuberculosis and subsequent fertility. Int J Gynecol Obstet. 1991;1-11:35.

11. Sutherland AM. The changing pattern of tuberculosis of the female genital tract. A thirty-year survey. Arch Gynecol. 1983;234:95-101.

12. Kubica GP, Dye WE, Cohn ML. Sputum digestion and decontamination with $\mathrm{N}$-acetyl-L-cysteine-sodium hydroxide for culture of mycobacteria. Am Rev Respir Dis. 1964;89:284-6.

13. Truffot-Pernot C, Véziris N, Sougakoff W. Modern diagnosis of tuberculosis. Presse Med. 2006;35:1739-46.

14. Brosch R, Gordon SV, Marmiesse M, Brodin P, Buchrieser C, Eiglmeier K, et al. A new evolutionary scenario for the Mycobacterium tuberculosis complex. Proc Natl Acad Sci U S A. 2002:99:3684-9.

15. Abebe M, Kidane D, Kirose K, Harboe M. Female genital tuberculosis in Ethiopia. Int J Gynaecol Obstet. 2004:84:241-6.

16. Jindal UN. An algorithmic approach to female genital tuberculosis causing infertility. Int J Tuberc Lung Dis. 2006:10(9):1045-50.

17. Margolis K, Wranz P, Kruger TF, Joubert JJ, Odendaal H. J. Genital tuberculosis at Tygerberg hospital - prevalence, clinical presentation and diagnosis. S Afr Med J. 1992;81:12-5.

18. Chavhan GB, Hiva P, Rathod K, Zacharia TT, Chawla A, Badhe P, et al. Female genital tuberculosis: Hysterosalpingographic appearances. Br J Radiol. 2004; 77(914):164-9.

19. Thangappah RBP, Paramasivan CN, Narayanan S. Evaluating PCR, culture \& histopathology in the diagnosis of female genital tuberculosis. Indian J Med Res. 2011:134:40-6.

20. Kohli MD, Nambam B, Trivedi SS, SB L, Arora S, Jain A. PCR-based evaluation of tuberculous endometritis in infertile women of North India. J Reprod Infertil. 2011;12(1):9-14.

21. Kulshrestha V, Kriplani A, Agarwal N, Singh UB, Rana T. Genital tuberculosis among infertile women and fertility outcome after antitubercular therapy. Int J Gynaecol Obstet. 2011:113:229-34.

22. Othieno E, Odida M, Gemagaine G, Okwi A, Bimenya GS, Wandabwa J. Female genital tuberculosis in Uganda. AJABS. 2008;30(2):30-4.

23. Kallenius G, Koivula T, Ghebremichael S, Hoffner SE, Norberg R, Svensson E, et al. Evolution and clonal traits of Mycobacterium tuberculosis complex in Guinea-Bissau. J Clin Microbiol. 1999;37(12):3872-8.

24. Halpern M, Castineiras M, Souza S, Hofer E, Martins S. Cavitary pneumonia caused by Rhodococcus equi in patient with AIDS. Int Conf AIDS. 1994;10:181

25. Taylor GM, Murphy E, Hopkins R, Rutland P, Chistov Y. First report of Mycobacterium bovis DNA in human remains from the Iron age. Microbiology. 2007:153:1243-9.

26. Taylor GM, Worth DR, Palmer S, Jahans K, Hewinson RG. Rapid detection of Mycobacterium bovis DNA in cattle lymph nodes with visible lesions using PCR. BMC Vet Res. 2007;3(1):12. 
27. Bahador A, Etemadi H, Kazemi B, Ghorbanzadeh R, Nakhjavan FA, Nejad ZA. Performance assessment of IS1081-PCR for direct detection of tuberculous pleural effusion: compared to rpoB-PCR. Res J Agric Biol Sci. 2005;1(2):142-5.

28. Derese Y, Hailu E, Assefa T, Bekele Y, Mihret A, Aseffa A, et al. Comparison of PCR with standard culture of fine needle aspiration samples in the diagnosis of tuberculosis lymphadenitis. J Infect Dev Ctries. 2012;6(1):53-7.

29. Sathe AV, Vaidya PR, Deshmukh MA, Motashaw ND. Genital tuberculosis in an endocrine clinic. J Obstet Gynaecol India. 1979;29:199-202.

Ready to submit your research? Choose BMC and benefit from:

- fast, convenient online submission

- thorough peer review by experienced researchers in your field

- rapid publication on acceptance

- support for research data, including large and complex data types

- gold Open Access which fosters wider collaboration and increased citations

- maximum visibility for your research: over $100 \mathrm{M}$ website views per year 